\title{
Relationship between bone density and bone metabolism in adolescent idiopathic scoliosis (AIS)
}

\author{
Yoichi Aota*, Ko Ishida, Nobuyuki Tanabe, Tomoyuki Saito \\ From 10th International Conference on Conservative Management of Spinal Deformities - SOSORT 2013 \\ Annual Meeting \\ Chicago, IL, USA. 8-11 May 2013
}

\section{Purpose}

Although osteopenia is often associated with AIS, studies on bone metabolism in relation to AIS have not yielded clear results. To characterize bone metabolism in AIS patients, a cross sectional study assessing bone metabolism and bone density was performed.

\section{Methods}

Using dual-energy $\mathrm{X}$ ray absorptiometry and bone metabolism markers (bone formation marker; BAP, bone resorption marker; TRAP5b), the bone mineral density of lumbar and bilateral proximal femurs were studied in 41 AIS patients aged 10 to 20 years old, with a mean of $15.2 \pm 5.9$ years old. Divided into two groups by levels of bone resorption marker (TRAP5b), BMD, BMI and age of menarche were compared statistically in each group.

\section{Results}

Among the AIS patients studied, osteopenia (-1 standard deviations to -2 standard deviations) was found in $34.1 \%$ of the patients and osteoporosis (below -2 standard deviations) was found in $24.4 \%$ of the patients. In 39 AIS patients (95.2\%), BAP values were within normal range. On the other hand, TRAP5b values were significantly high in $65.9 \%$ of the patients. In high levels of the TRAP5b group, BMD values of the lumbar spine and right femoral neck were significantly lower than those of the TRAP5b group.

\section{Conclusions and discussion}

The bone resorption marker was high in $65.9 \%$ of the AIS patients, and high bone resorption in bone metabolism

\footnotetext{
* Correspondence: yaota@yokohama-cu.ac.jp

Department of Orthopaedic Surgery, Yokohama City University, Yokohama,
} Japan

(c) 2013 Aota et al.; licensee BioMed Central Ltd. This is an Open Access article distributed under the terms of the Creative Commons

Submit your next manuscript to BioMed Central and take full advantage of:

- Convenient online submission

- Thorough peer review

- No space constraints or color figure charges

- Immediate publication on acceptance

- Inclusion in PubMed, CAS, Scopus and Google Scholar

- Research which is freely available for redistribution 